\title{
SOCIAL MEDIA PARTICIPATION IN URBAN PLANNING: A NEW WAY TO INTERACT AND TAKE DECISIONS
}

\author{
E. López-Ornelas ${ }^{\text {a }}$, R. Abascal-Mena a, S. Zepeda-Hernández ${ }^{\mathrm{a}}$ \\ ${ }^{a}$ Information Technology Department, Universidad Autónoma Metropolitana - Cuajimalpa, \\ Av. Vasco de Quiroga 4871, Ciudad de México - (elopez, mabascal, jzepeda)@ correo.cua.uam.mx
}

KEY WORDS: Social media participation, urban planning, sentiment analysis, user's analysis, textual analysis, community detection.

\begin{abstract}
:
Social Media Participation can be very important when you have to make an important decision about a topic related to urban planning. Textual analysis to identify the sentiment about a topic or, community detection and user analysis to identify the actors involved on a discussion can be very important for the persons or institutions that have to take an important decision. In this paper we propose a methodological design to analyse participation in social media. We study the installation of a new airport in Mexico City as a case of study to highlight the importance of conducting a study of this nature.
\end{abstract}

\section{INTRODUCTION}

Urban planning is a technical and political process concerned with the use of land and design of the urban environment, including air and water and infrastructure passing into and out of urban areas such as transportation and distribution networks. Urban planners are challenged to engage the public in meaningful ways to shape these planning processes (Borje et al., 2007).

In other hand, public participatory online applications aim to attract citizens to discuss current issues related to their environment and to improve the process of public participation in general. An integration of geographic information systems (GISs) with public participatory tools represents one of the latest innovations in this area. Recent research (Al-Kodmany, 2001; Rinner, 1999) discusses ways of integrating the new applications into participatory processes and considers which new functionalities and technical characteristics could offer the most benefit to users. New forms of collaboration and technical solutions emerged during the Web 2.0 era. For example, Google Maps and Google Earth can be used by lay users and nonexperts without intense training.

Finally, Social Media participation represents one type of tool that can be used to support interaction between groups of people who share a common interest (Livingstone et al., 2005; Christakis and Fowler, 2009; Sui and Goodchild, 2011). One of the features of many social networking tools is that they allow participants to microblog, the posting of short content, such as phrases, quick comments, images, or links to URLs, photos, audio, or video (Rattenbury et la. 2007; Lewis et al. 2010).

Social Media has become an essential component in our life (Borje et al., 2007). Social Media influences some aspects of human behavior from the way in which organizations operate to the way people shop and spend their time. Using Social Media, vast amounts of information can be disseminated to worldwide audiences in an instant, while the web simultaneously offers an arena for public and private social interaction.
Social network sites (SNS) can be defined as virtual collections of user profiles which can be shared with others (Borje, 2009).

Despite the prominence of the internet and social networking in modern life, research concerning information representation and visualization has been limited. We focus on the use of Twitter and the large amount of information that is generated daily.

Twitter is a popular social media service that allows people to share updates, news, and information with people in their Twitter network and beyond. In short, there is a large amount of information generated in social networks which is not properly explored or exploited by users or in our case, people who take decisions. Even if the tweets have a lot of information, there exists much more information that can be extracted and analysed automatically.

In this article we propose a methodological design process to in order to analyze the way the users interact with these urban topics, understanding who the actors are, how they are grouped and how they can help urban planners taking their decisions.

\section{SOCIAL MEDIA (TWITTER)}

If Twitter is a conduit for global stream of consciousness, it logically follows that the medium is a barometer for revealing everything, from occurrence of natural disasters to public perception of the city. In this paper we explore the potential awareness of this consciousness through the examination of Twitter and urban planning. Twitter can be understood as a new environment in which people gave their opinion about some problems in the cities.

Twitter is a popular social media service that allows people to share updates, news, and information (known at "tweets") with people in their Twitter network and beyond. In our approach we used tweets extracted from Twitter. A tweet is a little message of no more than 140 characters that users creates in order to communicate thoughts, feelings, or even participate in conversations. With over 200 million registered users (Halliday, 2011) and $13 \%$ of online Americans using Twitter (Smith, 
2011), Twitter is one of the most popular social media available. Research has compared Twitter to earlier kinds of social media like blogs (Java et al. 2007) and social network sites (Gruzd et al. 2011). Recent analyses of microblogging suggest that the brevity and broadcastability of messages are important affordances of microblogging.

First, and perhaps most promisingly, we believe that microblogging data can offer city planners and developers better information that can be used to improve planning and quality of life in cities. This might include new kinds of metrics for understanding people's interactions in different parts of a city, new methods of pinpointing problems that people are facing, and new ways of identifying potential opportunities for improving things.

\section{METHODOLOGICAL DESIGN PROCESS}

In this article we propose a new way of processing information; this is a design process that will help urban planners to analyze all the information contained in social networks. We have identified four important topics that must be studied and understood in order to know what is happening in the social network. These four topics are:

1. Structure analysis. This analysis is important to know who the actors that generate information are and the amount of information that flows in the networks and the interrelation that exists between the actors.

2. The sentiment analysis is an interesting topic that has to be understood. The tendency of opinion of the actors in order to analyse polarity of the information is very important for a specific urban planning project.

3. Community detection is very important element in order to simplify the social network and to identify some clusters (groups of users), who share similar opinions.

4. Finally, user identification can be very useful in order to identify the actors that are promoting different opinions.

In figure 1 we show a representation of this process

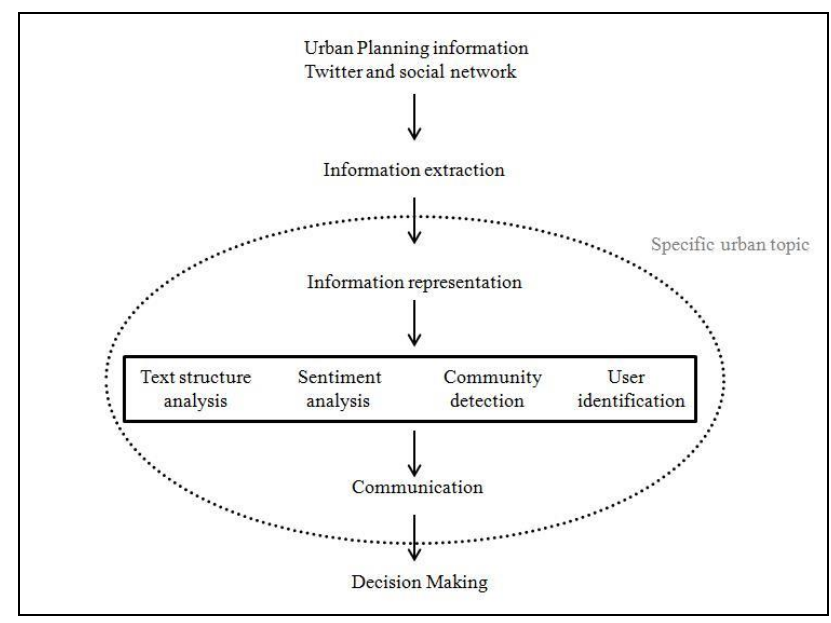

Figure 1. Proposed design process

This design process uses Social Media information and a set of technological techniques to perform a textual analysis in order to know what is being said on social networks and the user's analysis, who are the real people that is interacting with the social network. Such interaction analyzed must have obviously an urban component, where it is often linked to planning. A specific search using a \#hashtag to retrieve all different interactions, need to be applied. This is the first step, information extraction, and has to be done using an Application Interface defined by the social network, in our case Twitter (Twitter API, 2010), in order to store on a database. Some processing techniques have to be applied in order to analyze text and users by the urban planner (Marcus, 2011).

In the next section we explain how text analysis, community detection and user analysis are applied with a specific case of study.

\section{CASE OF STUDY \#NUEVOAEROPUERTO}

In this article we will discuss the installation of the new airport in Mexico City as a case of study. This installation represents a major infrastructure project to be performed in the center of Mexico City. This project has some encouraging opinions and some strong criticism. In this article we are interested in discover what people say in Social Media and who are the important users that represent a sort of activists in social networks.

The role of social media during the announcement of installation of the new airport in Mexico City gained great importance because Twitter became the principal media for the youngest people. Our analysis is based on all the tweets collected during this announcement.

The tweet allows the communication of texts, videos or pictures by providing a link to it. Some words of the tweet are preceded by the pound sing \# (hashtag). By using the hashtag, users can recover, reply (known as retweet) or follow conversations about a certain subject because this hashtag becomes automatically a hyperlink on Twitter. Everyone who clicks on a hashtag has the possibility to view the sear results of all other tweets that contains the same hashtag.

In our case, we used the hashtag \#nuevoaeropuerto, to recover all the conversations, ideas, phrases that were produced during the announcement of the installation of the new airport in Mexico City by the president of Mexico Enrique Peña Nieto.

\subsection{Structure identification}

The structure of the information is very interesting because we can identify some important elements of the tweet. In this way we can understand who generated the information and who only forward this information. The tweets that we recovered have different structures, for example:

"La sustentabilidad y el desarrollo económico del aeropuerto deben ir de la mano para lograr el proyecto que tanto necesitamos." (In English "Sustainability and economic development of the airport should go hand in hand to achieve the project we need.") This is the simplest structure where there is no image or any multimedia element associated to the text. Everything is represented using text. At this state, some Natural Language Processing (NLP) techniques can be applied to identify meaning of the text (Jurafsky, 2000). 

febrero@ @ carlosecaicedo@ @LINAPALMA @opinioncaribe@OpinaSantamarta@KARYMUCO @ELTIEMPO" (In English: "Works Airport StaMta initiate February@carlosecaicedo @LINAPALMA @opinioncaribe @OpinaSantamarta @KARYMUCO @ELTIEMPO”). This structure has mentions. A mention is a Tweet that contains another user's @ username anywhere in the body of the Tweet and this final user will be notifying about the tweet. Mentions are very important because we can identify all relationship that exists among users.

"Con el Nuevo Aeropuerto, no habrá problemas viales como se piensa http://t.co/cSnhHJYKZQ." (In English: "With the new airport, no traffic problems as you think http://t.co/cSnhHJYKZQ"). This structure shows different link. This link can be a web page or a blog. This structure is important because we can generate more information using this link, we can analyze and understand the real intention of this user.

"RT@pedestre: Plan de desarrollo urbano del aeropuerto es como Dios: dicen que existe, pero nadie lo ha visto" (In English: "RT @ pedestre: Urban planning of the airport is like God, he exists, but no one has seen him"). This structure has a retweet, that is a reposting of someone else's Tweet. Twitter's Retweet feature helps to share that Tweet with all of the followers. This structure revels that the user is not the author of the Tweet and the user only pass information.

$\bullet$

"Y hablando de \#impunidad. Primero era el problema \#Tlatlaya, ahora es el \#nuevoAeropuerto" (In English: "And talking of \#impunity, \#Tlatlaya was the first problem, now is the \#Newairport"). In this tweet is very important to analyze relationships among all different \#hashtags used in the text. People use the hashtag symbol \# before a relevant keyword or phrase (no spaces) in their Tweet to categorize those Tweets and help them show more easily in Twitter search. With this structure we can associate all different relates words with our search. This can be useful to detect polarity in the sentence.

\subsection{Sentiment Analysis}

Sentiment analysis is a growing area of Natural Language Processing with research ranging from document level classification (Pang and Lee, 2008) to learning the polarity of words and phrases (Esuli and Sebastiani, 2006). Given the character limitations on tweets, classifying the sentiment of Twitter messages is most similar to sentence-level sentiment analysis (Kim and Hovy, 2004); however, the informal and specialized language used in tweets, make Twitter sentiment analysis a very different task. It's an open question how well the features and techniques used on more well-formed data will transfer to the microblogging domain. Just in the past year there have been a number of papers looking at Twitter sentiment (Jansen et al. 2009. Other researchers have begun to explore the use of part-of-speech features but results remain mixed. Features common to microblogging like emoticons, are also common, but there has been little investigation into the usefulness of existing sentiment resources developed on nonmicroblogging data. (Davidov et al., 2010) also use hashtags for creating training data, but they limit their experiments to sentiment/non-sentiment classification.

The corpus defined in this case of study is a set of 1,400 tweets generated on September 2, 2014, the date on which the President of Mexico made the announcement of the installation of the new airport in Mexico City. This extraction is showed using a graph, where each node is the user that uses the hashtag \#nuevoaeropuerto and the arcs are interaction among users.

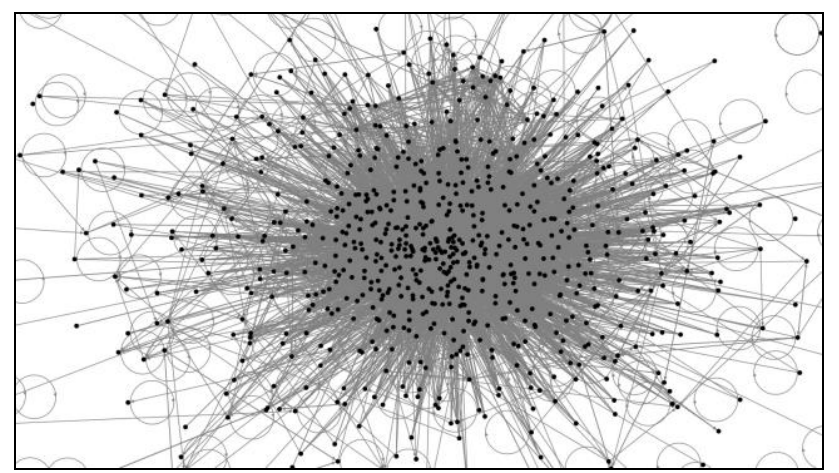

Figure 2. Graph visualization of the extracted information \#nuevoaeropuerto

The sentiment analysis showed in this article has been generated using the sentiment viz application developed by (Healey and Ramaswamy, 2010), that is an application to estimate and visualize sentiment for short, incomplete text snippets. Sentiment is defined as "an attitude, thought, or judgment prompted by feeling." The specific goal is a visualization that presents basic emotional properties embodied in the text, together with a measure of the confidence. In the figure 3 , we can detect that is a big concentration on opinions that are tense, active and alert, this is normally because is a new announcement of the government and all major actors are expecting the media reactions in order to have a real position of the announcement. We need to say that these sentiments are not an associated to any particular message but the intention of a set of messages.

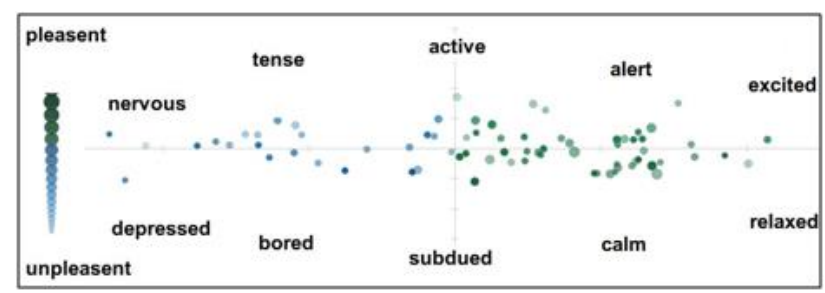

Figure 3. Sentiment analysis related to the hashtag \#nuevoaeropuerto, September 2, 2014.

In figure 4, we show the opinion of the same topic but two weeks later. We can see that almost all opinions are augmented and almost all passed of the status bored to the status active. Also, there are a large number of opinions that approve the project. This is due to the big media strategy generated by the government to manipulate the public opinion about the project. 
This analysis shows how opinion can change of one date to another in order to take a better decision about a topic.

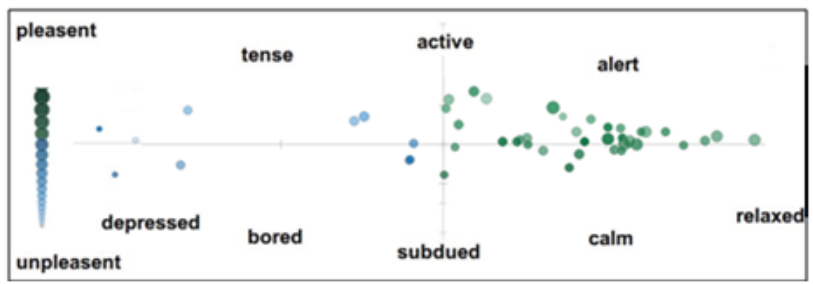

Figure 4. Sentiment analysis related to the hashtag \#nuevoaeropuerto, September 16, 2014.

\subsection{Community detection}

Society offers a wide variety of possible group organizations: families, working and friendship circles, villages, towns, nations. The diffusion of Internet has also led to the creation of virtual groups that live on the Web, like online communities. Indeed, social communities have been studied for a long time (Freeman, 2004). Communities also occur in many networked systems from biology, computer science, engineering, economics, politics, etc. We argue in this article that community detection can be very useful for urban planners because the different cluster of users can be identified.

A community can be defined as a set of nodes that are more densely connected to each other than to the rest of the network or that there is greater communication between them. The importance of this approach is that it is expected that nodes that are contained within the same community share attributes, common characteristics or functional relationships (Fortunato, 2010). However, there is no exact definition of what is, or how the network should be partitioned into a community.

In this article, we use "hierarchical maps" technique (Rosvall, 2008) to describe the dynamics of links and directed nodes, as well as weighted arcs to identify local interactions within the network. These local interactions allow calculating the flow of information that can be transmitted by the node, in other words, the degree of interconnection that exists between two nodes (Rosvall, 2008).

A group of nodes where information flows quickly and easily can be added and defined as module. The links between the modules and the times that were communicated allow the identification of the degree of connection between the modules, which allows a simplification of the group by generating a module and preserving the main node of this module or community. This process is repeated in order to get the final modules or communities (Figure 5). Using this community detection, we can simplify the graph and to identify important actors.

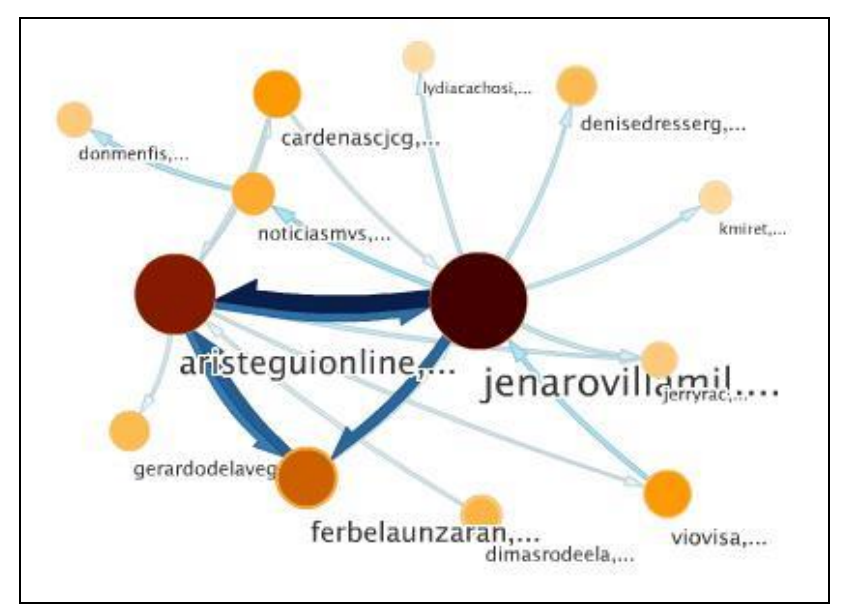

Figure 5. Community detection of the original network.

\subsection{User identification and classification}

In this process, the identification of users who are participating in this discussion is very important. In our case of study, we map the most important actors in the discussion who are obtained using community detection. Here we find several actors, for example: @ aristeguionline, @ gerardodelavega, @jenarovillan, @ denissegreserg, @ cardenascgcj, @ ferbelaunzaran, @ viovisa, @ noticiasmvs, @ donmenfils, @jerryrac, @lidiacachosi, @kmiret.

Despite the fact that the online community is a relatively young phenomenon, some of attempts in classifying internet users have been undertaken. For example, (Brandtzæg and Heim, 2011) propose a study that can be well adapted to the urban planning activism developed in this article. According to Brandtzaeg and Haim we can identify 5 different user classifications that reflect the intentions of all different users. This user classification is:

Sporadic. This kind of user visit social network from time to time, mainly to check if somebody contacted them.

- $\quad$ Lurkers is the largest group, they do not create any content, but consume and spread the content created by other groups. They are also notable for a propensity to time-killing.

Socializers use social networks to communicate and make interesting comments about a discussion. They need to be read and saw for multiple users. For example: @ aristeguionline, @ gerardodelavega.

Debaters are a more mature and educated version of socializers. Besides communication, less shallow than in the previous case, they are interested in consumption and discussion of news and other information available in social networks. For example,@jenarovillan, @denissegreserg, @ cardenascgcj.

Actives are engaged with all possible types of activity: communication, reading, creating, watching, and establishing groups. They have a strong criticism 
about a subject. Almost all users can are inside this category. For example, @viovisa, @ noticiasmvs, @donmenfils, @1 jerryrac.

Having this classification, decision makers may have better decision elements to analyze the behavior of the movement in the social network. With this analysis, we can detect who are the main actors or who is more important, even to detect the leader (the user that has a large number of followers, etc). All these elements define the strategy for the project and how to make better decisions for society.

\section{CONCLUSIONS}

The Social Media should be understood and taken as a medium that support the participatory process. In this paper we presented a review of advanced social media analysis method and tools, and an original process for textual analysis of Social Media Participation. Some techniques have been reviewed in order to discover potential suitable approaches for the integration of the Social Media Participation in urban and regional planning.

In this article we sought to understand Twitter's role in activist movements that are related on urban planning by exploring the specific case of the installation of the new airport in Mexico City. Diverse opinions (favorable and unfavorable) were presented in order to evaluate the sentiment associated to an important decision in different time. Also a user analysis is explored in order to categorize the different actors involved on a discussion.

In this article we argue that having all this information (users and sentiment analysis) can be very important in urban planning, because the person or institution that take the decision could have a lot of information and take better decisions. Specially in urban planning because the people is directly involved in this decisions.

In order to use Social Media efficiently for planning practice, it is necessary to encourage inclusion of all groups, through the promotion of systems, rising public awareness, and enabling an access to modern technology; also to choose a right tool, or multiple tools, in addition to the traditional ones. Another important topic is carefully study users of the system in order to determine exactly which group it does represent.

In conclusion, the knowledge of Social Media Participation if proficiently elicited might be used to discover and expose the will of users and could be a valid support for design, analysis and decision-making in urban and regional planning. Further research is definitely needed and Social Media analysis methods and technology should be applied from within real-life urban and regional planning process to proof the full efficacy. Nevertheless, early results are promising and the research agenda challenging.

This article took into account Twitter as the main element to perform the analysis, however, as future work is proposed to perform the analysis with other social media such as Facebook, Youtube, Instagram, Whatsapp, etc. To be able to make a comparison and to evaluate which social media generates better results.

\section{REFERENCES}

Al-Kodmany, K., 2001. Online tools for public participation. Government Information Quarterly, 18, 329-341.

Borge, R., Colombo, C., Welp, Y., 2009. Online and offline participation at the local level: A quantitative analysis of the Catalan Municipalities. Information, Communication \& Society 12, 899-928

Brandtzæg, P. B., Heim, J., 2011. A Typology of Social Networking Sites Users. International Journal of Web Based Communities, 7 (1).

Christakis, N.A., Fowler, J.H., 2009. Connected: The Surprising Power of Our Social Networks and How They Shape Our Lives. Little, Brown and Company.

Davidov, D., Tsur, O., Rapport, A., 2010. Enhanced sentiment learning using twitter hashtags and smileys. In Proceedings of Coling.

Esuli, A., Sebastiani, F., 2006. SentiWordNet: A publicly available lexical resource for opinion mining. In Proceedings of LREC.

Fortunato, S., 2010. Community detection in graphs. Physics Reports, 486(3-5):75-174.

Freeman, L. C., 2004. The Development of Social Network Analysis: A Study in the Sociology of Science (Book Surge Publishing).

Gruzd, A., Takhteyev, Y., Wellman, B., 2011. Imagining Twitter as an Imagined Community. American Behavioral Scientist, 55(10): 1294-1318.

Halliday, J., 2011. Guardian Activate 2011 Conference Live Blog. Guardian Activate 2011 Conference. Retrieved 2011, from http://www.guardian.co.uk/media/pda/2011/apr/28/ guardian activate-2011-new-york.

Healey, R., 2010. Visualizing Twitter Sentiment, from http://www.csc.ncsu.edu/faculty/healey/tweet_viz/

Jansen, B. J., Zhang, M., Sobel, K., Chowdury, A., 2009. Twitter power: Tweets as electronic word of mouth. Journal of the American Society for Information Science and Technology 60(11):2169-2188.

Java, A., Song, X., Finin, T., Tseng, B., 2007. Why we Twitter: Understanding microblogging usage and communities. Paper presented at the Joint 9th WEBKDD and 1st SNA-KDD Workshop '07, San Jose, CA.

Jurafsky, D., James M., 2000. Speech and Language Processing, Prentice-Hall.

Kim, S.-M., Hovy, E., 2004. Determining the sentiment of opinions. In Proceedings of Coling.

Lewis, S., Pea, R., Rosen, J., 2010. Beyond participation to cocreation of meaning: mobile social media in generative learning communities. Social Science Information 49, 351-369.

Livingstone, S., Bober, M., Helsper, E., 2005. Active participation or just more information? Information, Communication \& Society 8, 287-314. 
Marcus, M. S., Bernstein, O., Badar, D. R., Karger, S., Madden, R. C. Miller., 2011. Twitinfo: aggregating and visualizing microblogs for event exploration. In Proceedings of the 2011 annual conference on Human factors in computing systems, CHI '11, pages 227-236, New York, NY, USA ACM.

Pang, B., Lee, L., 2008. Opinion mining and sentiment analysis. Foundations and Trends in Information Retrieval 2(1-2):1-135.

Rattenbury T., Good N., Naaman M., 2007. Towards Automatic Extraction of Event and Place Semantics from Flickr Tags. In: proceeding of the 30th International ACM SIGIR Conference on Research and Development in Information Retrieval (pp. 103-110). New York, NY, USA.

Rinner, C., 1999. Argumentation maps - GIS-based discussion support for online planning. GMD research series no. 22. Sankt Augustin, Germany: GMD German National Research Center for Information Technology.

Rosvall, M., Bergstrom, C., 2008. Maps of random walks on complex networks reveal community structure. Proceedings of the National Academy of Sciences of the United States of America, 105(4):1118-1123.

Smith, A., 2011. Twitter update 2011. Pew Internet \& American Life: Washington DC.

Sui, D., Goodchild M.F., 2011. The convergence of GIS and social media: challenges for GIScience. In: International Journal of Geographical Information Science, Vol. 25, Issue 11, pp. 1737-1748.

Twitter API., 2010. http://apiwiki.twitter.com/ 